\title{
Knowledge Acquisition for Developing Knowledge-Base of Diabetic Expert System
}

\author{
IBRAHIM M.AHMED, MARCO ALFONSE, ABEER M.MAHMOUD, ABDEL-BADEEH M.SALEM \\ Computer Science Department \\ Faculty of Computer and Information Sciences \\ Ain Shams University, Cairo, Egypt \\ ibrahim1630@gmail.com,marco_alfonse@yahoo.com \\ abeer_f13@yahoo.com and abmsalem@yahoo.com
}

\begin{abstract}
Diabetes is a serious health problem today. Most of the people are unaware that they are in risk of or may even have type-2 diabetes. Type-2 diabetes is becoming more common due to risk factors like older age, obesity, lack of exercise, family history of diabetes, heart diseases . Along with good lifestyle and healthy diet, reduces the risk of development of type 2 diabetes for treatment of elder people, proper care of diet, exercise and medication as well is more important.. The research in developing intelligence knowledge base systems in diabetic domain is important for both health industry and diabetes patients. Recently expert systems technology provides an efficient tools for diagnosing diabetes and hence providing a sufficient treatment. The main challenge in building such systems is the knowledge acquisition and developing of the knowledge base of these systems. Our research was motivated by the need of such an efficient tool. The main objective of this paper is gathering knowledge acquisition for developing the knowledge base of diabetic type- 2 diet. Therefore, the paper presents the main phases of knowledge acquisition process on the development of fully automated healthy meal planner for diaptic-type-2.
\end{abstract}

Key-Words: expert systems - semantic network, diabetic diet, type 2 diabetes, rule-base.

\section{Introduction}

Diabetes is one of the major risky diseases for health care in our lives. If people were aware of the factors of diabetes and know how much risks they are of getting diabetes, diabetes may be prevented early [1]. Type 2 diabetes is a disease resulting from a relative, rather than an absolute, insulin deficiency with an underlying insulin resistance. Type 2 diabetes is associated with obesity, age, and physical inactivity [2, 3]. It is more common as compare to type-1 diabetes, usually 90 to $95 \%$. It is diagnosed in both adults and young people. In this type pancreas does not produce enough insulin to control keeping blood sugar level within normal ranges. Actually it is serious type of diabetes where mostly people are not aware they are suffering from it. Three major causes of diabetes type 2 are lifelong bad diet, inactive or sedentary lifestyle, and overweight [4].

On the other hand the research in developing intelligence knowledge base systems in diabetic domain is important for both health industry and diabetes patients .Expert system is a computer program that provides expert advice as if a real person had been consulted where this advice can be decisions, recommendations or solutions. A few numbers of expert systems are utilized in diabetic health research where each of these systems attempts solving part or whole of a significant problem to reduce the essential need for human experts and facilitates the effort of new graduates [5].
The paper is organized as follows. Section 2 presents major risk factors Diabetic Diet and Diabetic Food Pyramid. Section 3 describes the related work, and in section 4 present the knowledge acquisition and representation process. Conclusion is given in the last section.

2 Diabetic Diet and Food groups

2.1 Diabetic Diet

Diabetic Diet for diabetics is simply a balanced healthy diet which is vital for diabetic treatment. The regulation of blood sugar in the non-diabetic is automatic, adjusting to whatever foods are eaten. But, for the diabetic, extra caution is needed to balance food intake with exercise, insulin injections and any other glucose altering activity. This helps diabetic patient to maintain the desirable weight and control their glucose level in their blood. It also helps to prevent diabetes patient from heart and blood vessel related diseases [6].

Research shows that regardless of the makeup of the diet, eating just enough calories to maintain an ideal weight is the most effective dietary strategy to prevent the onset of diabetic. Recommendations of diabetic diet differ for person to person, based on their nutritional needs, lifestyle, and the action and timing of medications. [7]

In Type 2 diabetic, the concern may be more oriented to weight loss in order to improve the body's ability to utilize the insulin it does produce. Thus, learning about the basic of food nutrition will be able to help in 
adjusting diet to suite the particular condition. Recommended daily food portion contains carbohydrates, protein and fat. A Registered Dietitian assesses the nutritional needs of a person with diabetes and calculates the amounts of carbohydrate, fat, protein, and total calories needed per day. He will then convert this information into a recommended list of food for daily diet [7]. See table 1.

Table 1: Recommended daily food portion

\begin{tabular}{|l|l|}
\hline Nutrition & daily calories \\
\hline Carbohydrates & $(50 . .55) \%$ \\
\hline Protein & $(15 . .20) \%$ \\
\hline Fat & not more than $30 \%$ \\
\hline
\end{tabular}

\subsection{Diabetic Food Pyramid}

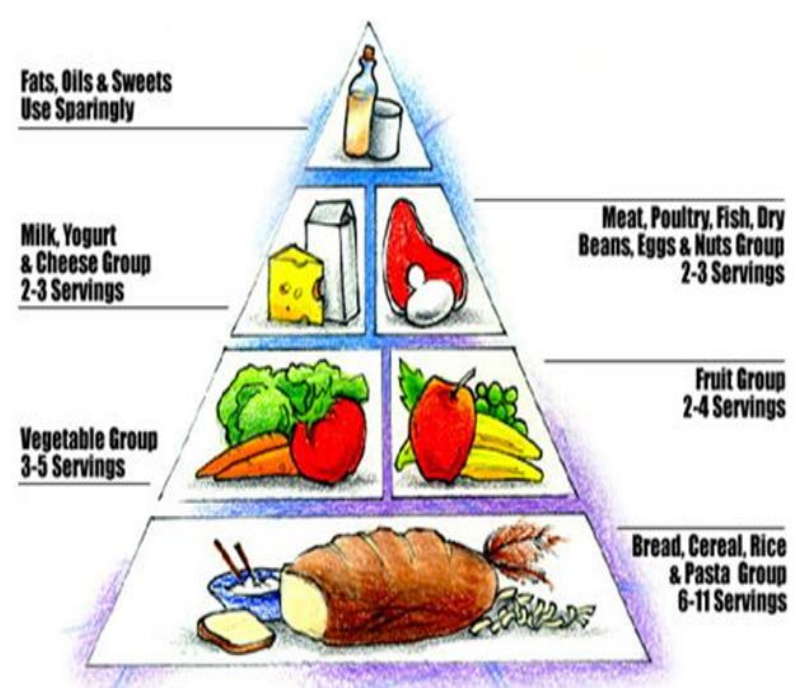

Figure 1: Food Pyramid

The Diabetes Food Guide Pyramid is a tool that shows how much you should eat each day from each food group for a healthy diet. The Diabetes Food Guide Pyramid is the best food guide for people with diabetes. The Diabetes Food Guide Pyramid places starchy vegetables such as peas, corn, potatoes, sweet potatoes, winter squash, and beans at the bottom of the pyramid, with grains. These foods are similar in carbohydrate content to grains. Cheese is in the Meat and others group instead of the Milk group because cheese has little carbohydrate content and is similar in protein and fat content to meat. [8].

Choosing foods from the Diabetes Food Guide Pyramid can help you get the nutrients you need while keeping your blood glucose under control [8].

Foods that are high in carbohydrates increase blood glucose levels and are in the Grains, Beans, and Starchy Vegetables group, the Fruits group, and the Milk group. Other foods that raise blood glucose are Sweets, found in the top of the Pyramid. Starchy foods, sweet foods, fruits and milk are high in carbohydrate. Foods lows in carbohydrates are found in the Vegetables group, Meat and Others group and Fats. Diabetes patient should eat 6 to 11 servings Grains, 2 to 5 servings Group Vegetable, 2 to 4 servings Group Fruit, 2 to 3 servings Group Milk, 2 to 3 servings group protein, Group sugars and oils should rarely be eaten [8].

\subsection{Food groups}

Food groups are exchange lists of foods that contain roughly the same mix of carbohydrates, protein, fat, and calories, serving sizes are defined so that each will have the same amount of carbohydrate, fat, and protein as any other. Foods can be "exchanged" with others in a category while still meeting the desired overall nutrition requirements. Food groups can be applied to almost any eating situation and make it easier to follow a prescribed diet. There are six food groups [9]:
1. Vegetables
2. Starches and Breads
3. Fruits
4. Milk
5. Fat
6. Meats and Meat Substitutes

The food groups are based on principles of good nutrition that apply to everyone. The reason for dividing food into six different groups is that foods vary in their carbohydrate, protein, fat, and calorie content. Each group contains foods that are alike; each food choice on a group contains about the same amount of carbohydrate, protein, fat, and calories as the other choices on that group [10].

\section{Related work}

M. Beulah et. al (2007) [11] introduced the ability to access diabetic expert system from any part of the world. They collect, organize, and distribute relevant knowledge and service information to the individuals. The project was designed and programmed via the dot net framework. The system allows the availability to detect and give early diagnosis of three types of diabetes namely type 1,2 , gestational diabetes for both adult and children.

W.Szajnar and G.Setlak(2011)[12] proposed a concept of building an intelligence system of support diabetes diagnostics, where they implemented start-of-art method based on artificial intelligence for constructing a tool to model and analyze knowledge acquired from various sources. The initial target of their system was to function as a medical expert diagnosing diabetes and replacing the doctor in the first phase of illness. Diagnostics the sequence of dealing with their system were as flow: (1) getting patient information and symptoms (2) competing basic medical examination in details (3) based on 
previous information the system find out whether the patient has diabetes and decides whether it is type 1 or type2. The systems used decision tree as a model for classification.

S. Kumar and B. Bhimrao (2012) [13] developed a natural therapy system for healing diabetic, they aim to help people's health and wellness, which don't cost the earth. Their main goal was to integrate all the natural treatment information of diabetes in one place using ESTA (Expert System Shell for Text Animation) as knowledge based system. ESTA has all facilities to write the rules that will make up a knowledge base. Further, ESTA has an inference engine which can use the rules in the knowledge base to determine which advice is to be given to the user. Their system begins with Consultation asking the users to select the disease (Diabetes) for which they want different type of natural treatment solution then describes the diabetes diseases and their symptoms. After that describes the Natural Care (Herbal /Proper Nutrition) treatment solution of diabetes disease.

Bayu Adhi Tama, Rodiyatul F. S. And Hermansyah [14] proposed and boosted algorithm acquires information from historical data of patient's medical records of Mohammad Hoesin public hospital in Southern Sumatera. Rules are extracted from Decision tree to offer decision-making support through early detection of Type-2 diabetes mellitus for clinicians, table 2 .

Table 2: Expert systems for diabetes

\begin{tabular}{|c|c|c|c|}
\hline \multirow{2}{*}{ Authors } & \multirow{2}{*}{ System purpose } & \multirow{2}{*}{$\begin{array}{c}\text { ML } \\
\text { technique }\end{array}$} & User interface \\
\hline & & & Application \\
\hline \multirow{2}{*}{$\begin{array}{l}\text { S.Kumar \& B. } \\
\text { Bhimrao 2012[13] }\end{array}$} & \multirow{2}{*}{$\begin{array}{l}\text { Integrate all the natural treatment } \\
\text { information of diabetes in one place }\end{array}$} & \multirow{2}{*}{ rule based } & Interactive \\
\hline & & & $\mathrm{Pc}$ \\
\hline \multirow{2}{*}{$\begin{array}{l}\text { W.Szajnar \& } \\
\text { Setlak 2011[12] }\end{array}$} & \multirow{2}{*}{$\begin{array}{l}\text { Model and analyze knowledge acquired } \\
\text { from various sources }\end{array}$} & \multirow[b]{2}{*}{ decision tree } & Interactive \\
\hline & & & $\mathrm{Pc}$ \\
\hline \multirow{2}{*}{$\begin{array}{l}\text { Bayu.A.T et.al } \\
2011[14]\end{array}$} & \multirow{2}{*}{$\begin{array}{l}\text { Bayu.A.T et.al 2011[14 ] } \\
\text { An Early Detection Method of Type-2 } \\
\text { Diabetes Mellitus in Public Hospital }\end{array}$} & \multirow[t]{2}{*}{ decision tree } & Request /Response \\
\hline & & & $\mathrm{Pc}$ \\
\hline \multirow{2}{*}{$\begin{array}{l}\text { P. M. Beulah et.al } \\
2007[11]\end{array}$} & \multirow{2}{*}{$\begin{array}{l}\text { Detect and give early diagnosis of three } \\
\text { types of diabetes for both adult and } \\
\text { children }\end{array}$} & \multirow[t]{2}{*}{ Rule based } & Request /Response \\
\hline & & & $\mathrm{Pc}$ \\
\hline
\end{tabular}

4. Knowledge acquisition and representation

\subsection{Knowledge acquisition}

Knowledge acquisition is a very important phase in developing expert systems [4]. Our knowledge has been gained by consultation of nutritionist. Actually, knowledge acquisition required time of three months form major Ibtehal and Nasik nutritionist of diabetes in the military hospital in Khartoum, in addition to some related books and internet medical web sites. In addition we determine the amount of each item in the food groups in table 3 . 
ICIT 2015 The 7th International Conference on Information Technology

doi:10.15849/icit.2015.0004 (C) ICIT 2015 (http://icit.zuj.edu.jo/ICIT15)

Table 3: Standards of items

\begin{tabular}{|l|l|l|l|l|l|}
\hline \multicolumn{2}{|l|}{ Fat \& Milk } & \multicolumn{2}{c|}{ Sugar } & \multicolumn{2}{l|}{ Proteins } \\
\hline Name & Amount & Name & Amount & Name & Amount \\
\hline Oil & Spoon(20 gram) & Sugar & Spoon(20 gram) & Chicken & $1 / 4$ piece(250 gram) \\
\hline Shortening & Spoon(20 gram) & Jam & Spoon(20 gram) & Egg & 1 piece \\
\hline Synths & Spoon(20 gram) & Cake & 1 piece & Fish & 125 gram \\
\hline Milk & 1 cup & Tahnia & Spoon(20 gram) & Meat & 100 gram \\
\hline Yogurt & 100 gram & Sweet & 1 piece & Tamiea & 4 pieces(40 gram) \\
\hline Cheese & 50 gram & S_drinks & 75 ml & Bean & 100 gram \\
\hline- & - & Basta & Small piece & Lentils & 100 gram \\
\hline- & - & - & - & Fual & 100 gram \\
\hline & Fruits & & Vegetables & & Starch \\
\hline Name & Amount & name & Amount & Name & Amount \\
\hline Banana & Small piece(100 gram) & Salad & Free & Custer & 1 cup \\
\hline Orange & Small piece(100 gram) & Molokhia & 100 gram & Kissra & 2 pieces(100 gram) \\
\hline Mango & Small piece(100 gram) & Eggplant & 100 gram & Gorasa & $1 / 2$ piece (100) \\
\hline Dates & 3 pieces(24 gram) & Dried & 100 gram & Bread & 1 piece (120 gram) \\
\hline Grapes & 10 pieces (120 gram) & Potatoes & 200 gram & Rice & 1 cup \\
\hline W_melon & 2 slice(120) & Regala & 200 gram & Pasta & 1 cup \\
\hline Apple & Small piece(100 gram) & Taglia & 100 gram & Potato & Big piece \\
\hline Guava & Small piece(100 gram) & Roub & 200 gram & Noodles & 1 cup \\
\hline
\end{tabular}

Kissra, Gorasa: kind of bread

\subsection{Knowledge representation}

Knowledge representation allows one to specify and emulate systems of a growing complexity. Knowledge representation schemes indeed have known an important evolution, from basic schemes supporting a rather heuristic approach, to advanced schemes involving a deeper consideration of the various dependencies between knowledge elements [15]. The main Types of diabetes are Type1, Type 2 and Gestational [16].figure 3 describes Knowledge representation of the diabetic serving.

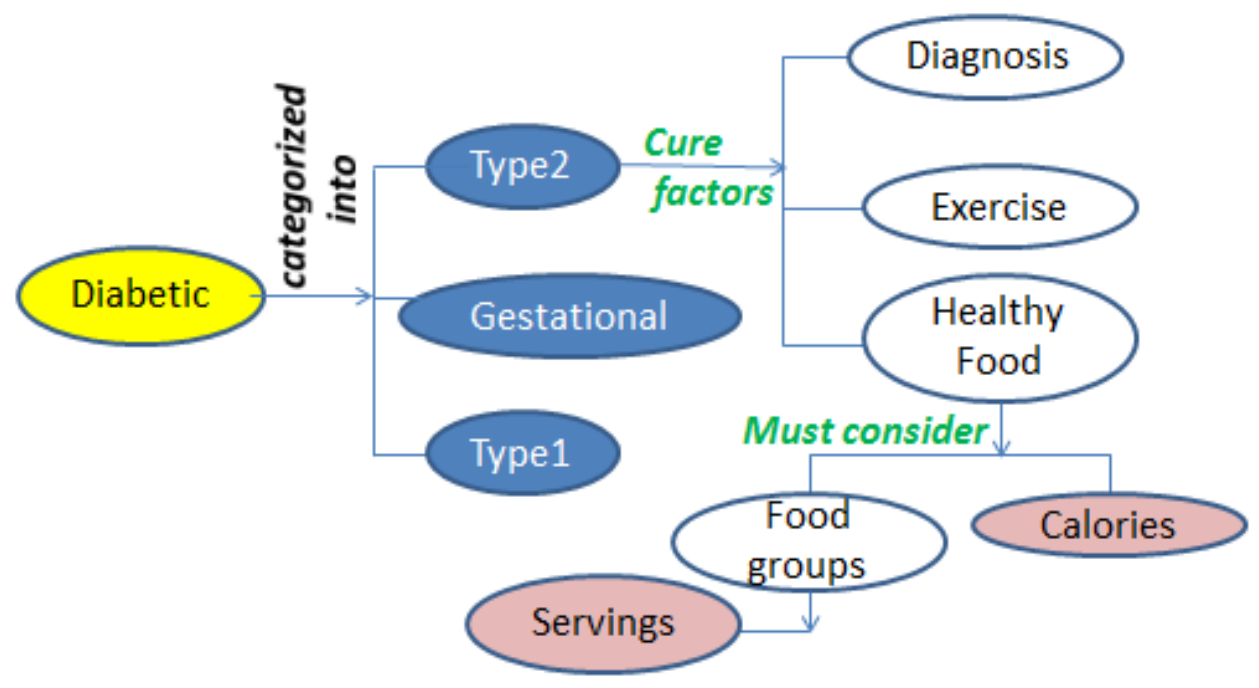

Figure 3: knowledge representation 


\subsection{Food groups servings}

Some diseases increase the risk of diabetic disease and affect the number of serving in the food groups, the major diseases we get from our Knowledge acquisition are Anorexia, Surgery, Blood pressure, Typhoid, Bitter,
Liver problems, Heart disease and Gout . Other factors affect the serving are the patient activity, and weight see fig 4 . The figure shows the relation of food groups and serving allowed for each group for the diabetic patient.

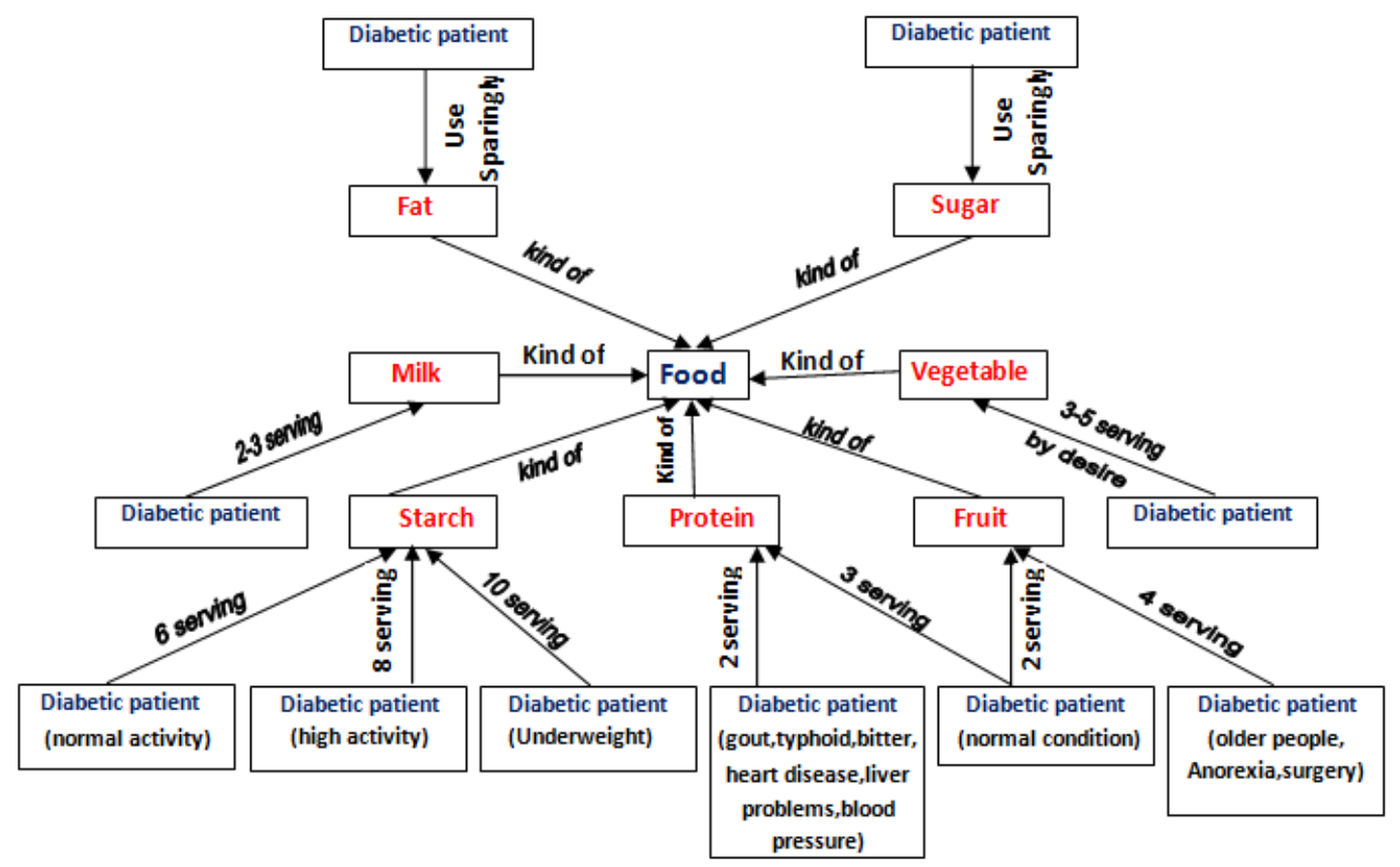

Figure 4: Semantic network for food groups servings

\section{4 knowledge management}

The following is the algorithm to specify the numbers of serving to each patient according to fig 4 .

1. Determine whether the patient is slim or moderate or obese.

2. Determine whether the patient activity is high or moderate or little.

3. Determine whether the patient infected with (Anorexia, Surgery, Blood pressure, Typhoid, Bitter, Liver problems, Heart disease, Gout)

4. Calculate number of servings as follows:

Vegetable- servings $=3$

If (anorexia $=1$ ) or (surgery=1) or (age $>65)$ then fruitservings $=4$ else fruit- servings $=2$

If activity="normal" then crabs-servings $=6$

Else if activity="high" then crabs-servings $=8$
If the patient underweight then crabs-servings $=10$

If $(($ gout $=1)$ or $($ Heart disease $=1)$ or $($ Bitter $=1)$ or $($ liver problems $=1)$ or $($ Blood pressure $=1)$ or $($ Typhoid $=1))$ then protein-servings $=2$ else protein-servings $=3$

If $(($ gout $=1)$ or $($ Heart disease $=1)$ or $($ Bitter $=1)$ or $($ liver problems $=1)$ or $($ Blood pressure $=1)$ or $($ Typhoid $=1)$ then milk-servings $=2$ else milk-servings $=3$

\section{Conclusions}

Type-2 diabetes is the most common form of diabetes. This paper presents the first phase of developing an efficient expert system for diabetic Type-2 diet. The structure of the system contains three steps. First calculate total needs of calories, second determines the amount calories of the items and finally determines the proper diet.

Self-monitor for patient of type 2 diabetes is possible by getting proper amount of daily proper diet satisfy the amount of calories. The servings of meals calculate according to Body Mass Index (MBI) and the type of activity for the patient and the additional patient diseases. The food groups contain the same amount of carbohydrate, protein, fat, and calories Sudanese food 
groups contains different meals so you don't have to eat the same foods all the time.

After collecting knowledge and perform the necessary analysis semantic network and food serving representation, Currently we are working on developing mobile-based expert system in Arabic language interface for diabetes diet that intended to be used in Sudan and Arab countries .

References:

[1] Huiqing H. Yang and Sharnei Miller, "A PHP-CLIPS Based Intelligent System for Diabetic Self-Diagnosis", Department of Math \& Computer Science, Virginia State University Petersburg, 2006.

[2] Edward H. Shortliffe, Leslie E. Perreault, et al, Medical Informatics: Computer Applications in Health Care and Biomedicine, Springer-Verlag New York, Inc, 2001.

[3] Federal Bureau of Prisons Management of Diabetes Clinical Practice Guidelines June 2012.

[4] David Forbes, Pornpit Wongthongtham and Jaipal Singh, "Development of Patient-Practitioner Assistive Communications (PPAC) Ontology for Type 2 Diabetes Management", Curtin University, Perth, Australia, 2013.

[5] Byoung-Ho Song, Kyoung-Woo Park and Tae Yeun Kim. "U-health Expert System with Statistical Neural Network", Advances on Information Sciences and Service Sciences. vol. 3, no.1, pp 54-61, 2011.

[6](2013)[Online].Available:http://www.medmint.com/ CONTENT/Diabetics/Diabetics_7.html Diet for diabetes patient.

[7]Igbal.A and Nagwa. M,"health guide for diabetics", Sudan Federal ministry of health, 2010.

[8] Mario A Garcia, Amit J.Gandhi, Tinu Singh, Leo Duarte, Rui Shen, Maruthi Dantu Steve Ponder, and Hilda Ramirez. "ESDIABETES (AN EXPERT SYSTEM IN DIABETES)", JCSC 16, pp 166-175. 2001.

[9](2012)[Online].Available:http://www.diabetesdiabetic-diet.com,--"Diabetes Education and Prevention" World Diabetes Day.

[10](2013)[Online].Available:http://www.glycemic.com/ DiabeticExchange," The Diabetic Exchange List.

[11] P. M. Beulah Devamalar, V. Thulasi Bai, and Srivatsa S. K. "An Architecture for a Fully Automated Real-Time Web-Centric Expert System", World Academy of Science, Engineering and Technology, 2007.
[12] Wioletta SZAJNAR and Galina SETLAK. "A concept of building an intelligence system to support diabetes diagnostics", Studia Informatica, 2011.

[13] Sanjeev Kumar and Babasaheb Bhimrao, "Development of knowledge Base Expert System for Natural treatment of Diabetes disease", (IJACSA) International Journal of Advanced Computer Science and Applications, Vol. 3, No. 3, 2012.

[14] Bayu.A.T et.al," An Early Detection Method of Type-2 Diabetes Mellitus in Public Hospital “, 2 TELKOMNIKA, Vol.9, No.2, pp. 287-294, August 2011.

[15] Stephan Grimm, Pascal Hitzler and Andreas Abecker," Knowledge Representation and Ontologies Logic, Ontologies and SemanticWeb Languages", University of Karlsruhe, Germany, pp 37-87, 2007.

[16] Abdulla Al-Malaise Al-Ghamdi et al," An Expert System of Determining Diabetes Treatment Based on Cloud Computing Platforms", International Journal of Computer Science and Information Technologies, Vol. 2 (5), pp 1982-1987, 2011. 